\title{
How well are the Elite Players Performance Plan (EPPP) supporting young players with Psychological Welfare?
}

\begin{abstract}
The aim of this report was to assess how well equipped and supported Heads of Education feel in maintaining and promoting psychological welfare of young footballers, within their setting, as directed by the EPPP. Based on Wylleman \& Lavallee $^{1}$ it was considered there are many stressors affecting young pros around maturation and transition. Similarly Brown $\&$ Potrac $^{2}$ argue that it is a build-up of resilience strategies that determine psychological welfare success. Six semi-structured interviews were conducted with Heads of Education, Welfare and Safeguarding at six football academies throughout the English Football Leagues. The findings revealed that parents, injuries and peers were the main psychological stressors facing young football players. The main strategies in place to combat the effects of these for players were found to be holding workshops, and maintaining reflective journals. Consistently, money and time were the major battles Heads of Education, Welfare and Safeguarding faced in delivering these methods successfully. The EPPP was considered to have brought psychological welfare towards the frontline of academy provision but was still very much behind technical and physical player development.
\end{abstract}

Volume 9 Issue $3-2018$

\author{
Susan Jones \\ Department of psychology, Manchester Metropolitan University, \\ UK
}

Correspondence: Susan Jones, Manchester Metropolitan University, England, UK, Email suejones5@outlook.com

Received: February 1, 2018 | Published: June 14, 2018

\section{Introduction}

Most mental health concerns are reserved for diagnosis in over $18 \mathrm{~s}$ according to the Diagnostic Statistical Manual. ${ }^{3}$ However, Alfermann ${ }^{4}$ noted that more youth cases of items such as depression and anxiety disorders are increasingly occurring in adolescents, especially those under competitive anxiety. Wylleman \& Lavallee, ${ }^{1}$ also identify friendship alterations around life changes as Finn \& McKenna ${ }^{5}$ suggest; and hormonal and maturational stressors. When considering athletes, these transitional shifts also factor academy to first team progression; lifestyle, and retirement, especially if forced due to an injury as Drahota \& Eitzen ${ }^{6}$ identified. Furthermore, Brown $\&$ Potrac $^{2}$ acknowledged short-term stressors such as deselection, and the humiliation that can follow, as well as the loss of identity and camaraderie that can occur with deselection, injury and retirement. Whilst the Professional Player's Association (PFA) 7 are attempting to support players with these transitions with publications such as, "Life and How to Handle it", ${ }^{7}$ it is the day-to-day support that ultimately impacts on young pros.

Understandably however, it is considered that young footballers must show strength of coping in these areas from a young age in order to progress. Holt \& Dunn ${ }^{8}$ along with Sagar ${ }^{9}$ identify that resilience is a key quality in coping with the fiercely competitive and disciplined environment of professional football. On the other hand, it is paramount that clubs have ways of carefully managing this process throughout the progression stages, in order for players to successfully manage their anxieties (Holt and Mitchell, 2006). Various ways have been suggested in terms of doing this. Reflexive reports have been used by Raelin ${ }^{10}$ and Richards et al., ${ }^{11}$ as a way of documenting day-today emotions; also relabelling negative emotions has been suggested by Brannen \& Petite, ${ }^{12}$ in order to decrease stigma and connotations of anxiety and stress and meaning-focused coping as identified by Folkman \& Moskowitz, ${ }^{13}$ whereby players use goal-setting as a way of building resilience against negative thought processes.
In 2011, the Football Association (FA) introduced the EPPP programme, designed to provide a "Holistic Development Programme" for young pros, whilst developing the four key areas of the FA's curriculum, Physical, Technical, Social, and Psychological development (The FA, 2009). The psychological pathway is concerned with understanding, decision making and confidence, however these all apply to the physical game. The FA have outlined, within the $\mathrm{EPPP}^{14}$ that research questions around "Measuring players' motivation and potential to manage game related stress", (EPPP ${ }^{14} \mathrm{p}$. 76) should be carried out to guide later updates to the programme. However there are no clear directions or guidance relating to how or when this should be done. Furthermore, within staffing, only Category 1 and 2 academies are required to have a full time Welfare and Safeguarding position (EPPP $\left.{ }^{14}\right)$; whilst, Category 3 and 4 clubs may use their Head of Education to fulfil this role and could also allocate this as part time (EPPP, ${ }^{14}$ p $86 \&$ 87). This raises some concerns, as this Head of Education is also a member of the Academy's Senior Management Team; therefore the validity of their contributions if only part time whilst managing two simultaneous roles should be questioned. Even for roles where this positioned is covered full time, it can be argued that Safeguarding requires very different day to day management that psychological expertise and player welfare, however there are no requirements, even in Category 1 and 2 clubs, to employ psychological support staff specific to these roles. This research therefore focuses on how well equipped and supported the Head of Education feels in maintaining and promoting psychological welfare within their setting.

\section{Method}

\section{Participants}

Participants were selected via their career profiles on an online networking site. Criteria was set at participants needing to be currently working in either a Professional Phase coaching capacity or as Head of Education and/or Welfare Officer at a Category 1-4 Academy 
within the top four English Football League system. They also had to have had previous experience of working in English Football Academies or Centres of Excellence prior to the EPPP ${ }^{14}$ introduction in 2011 for comparable purposes. All participants were given the opportunity to allow their identities' be used or to have this protected via pseudonyms. However it should be noted that all participants in this study opted for pseudonyms to be used. The researcher must also highlight that some areas of interviews were asked to be kept confidential by participants and not be used within this report, and therefore this has been respected by denoting "(name omitted)" in results (PAGE). Of those originally contacted the final participant demographic was as follows: Coaches $\mathrm{N}=1$, Heads of Education $\mathrm{N}=2$, Welfare Officers $\mathrm{N}=3$. Category 1 Clubs represented $\mathrm{N}=1$, Category 2 clubs represented $\mathrm{N}=3$, Category 3 clubs represented $\mathrm{N}=1$, Category 4 Clubs represented $\mathrm{N}=1$, as can be seen in Table 1. Whilst it is noted that an even sample number is not represented for all categories, it was considered that a fair spread of category representation was included.

\begin{tabular}{llll}
\hline $\begin{array}{l}\text { Participant } \\
\text { number: }\end{array}$ & $\begin{array}{l}\text { Represented } \\
\text { academy } \\
\text { rating (I-4) }\end{array}$ & $\begin{array}{l}\text { Participant's } \\
\text { experience } \\
\text { (Years) }\end{array}$ & $\begin{array}{l}\text { Job position } \\
\text { held }\end{array}$ \\
\hline 1 & 1 & 8 & Head of Education \\
2 & 3 & 15 & Head of Education \\
3 & 2 & 10 & Welfare Officer \\
4 & 2 & 8 & $\begin{array}{l}\text { Welfare Officer } \\
\text { Welfare Officer } \\
5\end{array}$ \\
2 & 2 & 7 & $\begin{array}{l}\text { Coach/Welfare } \\
\text { Officer }\end{array}$ \\
\hline
\end{tabular}

\section{Semi-structured interviews}

Each interview was conducted at the Academy setting from which the participant worked. Before commencement, each participant was asked to read the participant information sheet, complete an informed consent form and fill in a demographic sheet about themselves and their academy for time saving purposes. Questions were focused around gaining an insight into their background familiarity with psychological welfare practice, which went on to ask about their specific experiences of running this aspect at their setting as well as how supported they feel by the FA in terms of fulfilling the role in line with strict EPPP ${ }^{14}$ guidelines. This procedure is supported by Dale ${ }^{15}$ to keep interviews focused and on-topic. Furthermore using semistructured interviews allows higher internal validity to be generated from the interview schedule also as Levitt ${ }^{16}$ suggested, whilst allowing some flexibility for participants to expand where they deem necessary, as supported by Cote et al. ${ }^{17}$ All interviews were recorded on a Samsung S7 mobile device as this was regarded as unobtrusive and not unfamiliar with clients.

\section{Data analysis}

All interviews were word processed and transcribed verbatim as prescribed by Kvale. ${ }^{18}$ Smith $^{19}$ identified that grouping data sets is useful for comparisons to be drawn, therefore thematic analysis was used to analyse participant responses. Firstly transcripts were colour coded into sections relating to "Psychological Issues", "Resilience
Strategies", and "Analysis". Whereby common psychological issues could be extracted as suggested by Biddle, ${ }^{20}$ the Academy responses to coping and building resilience of these strategies, and lastly how well the participants perceived these to work effectively. Once grouped, the data was re-analysed to look for commonalities between issues and coping strategies for within and between category analysis. Furthermore the key question relating to contract release was considered separately and was analysed as to the similarity to club culture and club values. The reliability of this method was considered useful by Patton, ${ }^{21}$ as it uses objectivity in analysis, despite the researcher's familiarity with the peer- reviewed psychological literature it is looking for comparisons with.

\section{Results}

Table 2, Table 3, Table 4 below, show the primary, secondary and tertiary stressors that were considered to act on players according to participants. These were derived from thematic analysis of the interview transcripts and then grouped into the sections from the question around the most difficult psychological issue they find in supporting players. Once this data was compiled, the themes were then grouped into main "Psychological Issues" (Table 5), most practiced "Resilience Strategies" to combat these psychological stressors (Table 6) and "Future Directions" (Table 7), which focused on the barriers that Welfare and Education departments face, in terms of combating these psychological issues and ensuring the success of their resilience strategies within their settings.

\section{Table 2}

\begin{tabular}{llll}
\hline $\begin{array}{l}\text { Participant } \\
\text { number: }\end{array}$ & $\begin{array}{l}\text { Primary } \\
\text { stressor } \\
\text { identified }\end{array}$ & $\begin{array}{l}\text { Resilience } \\
\text { strategy of } \\
\text { primary stressor }\end{array}$ & $\begin{array}{l}\text { Main barrier } \\
\text { of strategy } \\
\text { effectiveness }\end{array}$ \\
\hline I & Parents & Workshops & Knowledge \\
2 & Injury & $\begin{array}{l}\text { Journals } \\
\text { Disciplinary }\end{array}$ & Staff \\
3 & Peers & Procedures & Time \\
4 & Injury & Keep Involved & Time \\
5 & Injury & Keep Involved & Time \\
6 & Parents & Inform Them & Money \\
\hline
\end{tabular}

Table 3

\begin{tabular}{|c|c|c|c|}
\hline $\begin{array}{l}\text { Participant } \\
\text { number: }\end{array}$ & $\begin{array}{l}\text { Secondary } \\
\text { stressor } \\
\text { identified }\end{array}$ & $\begin{array}{l}\text { Resilience strategy } \\
\text { of secondary } \\
\text { stressor }\end{array}$ & $\begin{array}{l}\text { Main barrier } \\
\text { of strategy } \\
\text { effectiveness }\end{array}$ \\
\hline I & Injury & Journals & $\begin{array}{l}\text { Time } \\
\text { (paperwork) }\end{array}$ \\
\hline 2 & Parents & Workshops & Staff \\
\hline 3 & Injury & Journals & Time \\
\hline 4 & Injury & Keep Involved & $\begin{array}{l}\text { Player } \\
\text { Motivation }\end{array}$ \\
\hline 5 & Parents & Feel Involvement & Time \\
\hline 6 & Injury & Keep Involved & Money \\
\hline
\end{tabular}


Table 4

\begin{tabular}{|c|c|c|c|}
\hline $\begin{array}{l}\text { Participant } \\
\text { number: }\end{array}$ & $\begin{array}{l}\text { Tertiary } \\
\text { stressor } \\
\text { identified }\end{array}$ & $\begin{array}{l}\text { Resilience } \\
\text { strategy of } \\
\text { tertiary stressor }\end{array}$ & $\begin{array}{l}\text { Main barrier } \\
\text { of strategy } \\
\text { effectiveness }\end{array}$ \\
\hline I & Agents & $\begin{array}{l}\text { Disciplinary } \\
\text { Procedures }\end{array}$ & $\begin{array}{l}\text { Player } \\
\text { Motivation }\end{array}$ \\
\hline 2 & Peers & Self-Management & $\begin{array}{l}\text { Player } \\
\text { Personalities }\end{array}$ \\
\hline 3 & Parents & Workshops & Time \\
\hline 4 & Peers & $\begin{array}{l}\text { Disciplinary } \\
\text { Procedures }\end{array}$ & Time \\
\hline 5 & Peers & Self-Management & $\begin{array}{l}\text { Player } \\
\text { Personality }\end{array}$ \\
\hline 6 & $\begin{array}{l}\text { Lifestyle } \\
\text { Management }\end{array}$ & $\begin{array}{l}\text { Disciplinary } \\
\text { Procedures }\end{array}$ & Staffing \\
\hline
\end{tabular}

Table 5 Table showing the psychological issues of players in highest ordered themes

\begin{tabular}{ll}
\hline Stressor & Theme order \\
\hline Parents & 1 \\
Injury & 2 \\
Peers & 3 \\
\hline
\end{tabular}

Table 6 Table to show the most common future directions and changes with the theme order identified

\begin{tabular}{ll}
\hline Direction & Theme order \\
\hline Time & 1 \\
Money & 2 \\
Training & 3
\end{tabular}

\section{Psychological issue}

Participants all noted that the main welfare issues players faced were:

a. Parents $(n=4)$, the main issue perceived by Welfare and Safeguarding Officers was around the disparity of coaching philosophy and parental investment. (e.g., "However youse do something here (the club) there's always the problem of when they go home... how'd the parents question 'em, do they make comments etc." [P6]). In some cases this was considered more so by home-grown players than ones who come in from abroad to stay with host families $(\mathrm{N}=1)$ (e.g. for the lads that stay it's not so bad, then we get into other problems like, their agents and stuff... but for them, it's easier as they want to do well and they maybe take their time a bit more, they don't have so much in terms of outsider messages". [P1]). Whilst it was noted in this response that parents were still supportive of their child's development, the overriding message was that in day-to-day occurrences oversees players were more immune from parental influence as it is the players themselves who report back about progress via phonecalls and social media.

b. Injury ( $n=6$ ), Injuries were found to be the second most difficult stressor for players to overcome. Potentially as they can be unexpected, severe and at times where players have placed significant importance e.g. cup games, (e.g., "Injuries are just the worst, there's nothing you can do but check in on them, like make sure they're ok with it and stuff... like they still feel part of what's happening" [P2]. Whilst it was noted that clubs place significant importance on Strength and Conditioning, it was felt this could be better synergised in future, (e.g. You can do all the prep you like, weights, running, offseason, as you know! (Laughs)...but you can never prepare them for that mental part, like how long they'll be out...is the... coach looking to boost you up [in training] or whatever", [P5]).

c. Peers $(n=4)$, Peer influence was found to be a contributing factor in terms of time spent with peers versus importance of self-care. It is noted that agents were also mentioned in this section but were considered for analysis as a "Future Direction" factor, given the nature of responses, (e.g. "Generally they're all good lads, but you have to be careful like if they've done something with me or "John" that's given them a beef [like competing for class votes] then it can be a factor, like you might see them the next day and their different for a while", [P3]). Individual personality management was a factor coaches found more difficult, (e.g. "You never want to get rid of personality but sometimes if you take on a boy you think is a bit of a handful it can affect the others, you have to like... manage the group and not make an issue out of things...we had a situation last year where a lad came in with his pink boots, we told him its black boot only and he got a bit...you know, but its important the group sees us doing that" [P4].

\section{Resilience strategies}

a. Injury was the most targeted section as this was felt to be mostly within the club's control, keeping players involved was one area of resilience $(n=4)$, (e.g. "Making them feel their still here, like they still have that opportunity...like it's not just a one-off thing, like they still come in everyday and are around the rest of the coaches and that", [P4]). Also, the use of journals and role modelling was considered an effective strategy, (e.g. "We get the lads to write about the time injured cos then we can use it, for others, its great cos they feel like they're helping us but they're also helpin themselves", [P3]. This latter response is also a supporting example of reflecting on injuries as a method of support along with, (e.g. "Aye we do get them to use these journal things, I'll get you one later, where they write about their rehab and that", [P2]). Using other staff was also a feature in one club, (e.g. "Well we've got "Sam" in here now, who's been great for the lads, he'll have a laugh and joke with them, take them down to the gym and do it all with them...that's been great for us", [P5]).

b. Parents were seen as a more difficult subject to be able to tackle directly, although all participants noted that this was the more common area of stress. Workshops were one way of attempting to change parent's ideals $(n=3)$, (e.g. "The parents get invited in pre-season, well... and during the season, to have a kind of informal chat about what the club is and where its going and... what we want our lads to be doing...some of the parents love it cos they kind of feel involved but you'll always have the ones that...you know...played for Carlisle once when they were 12 or whatever", [P2]); e.g. well invite them in once or twice a year and tell them what's been happening, what we've done, etc, what they can be doing with them at home to help that etc, [P3]. The second most popular strategy was around keeping parents involved and updating their knowledge $(n=2)$, (e.g. "If you give them something to do, then their focus is away from what we're 
doing, having a family atmosphere to the place um, helps us to help the lads", [P5]). Interestingly one participant identified money was also a factor around causing disparities between parents and coaches, (e.g. "You'll always get the ones [parents] asking why we don't do what (names omitted) do, and you're like, we're (name omitted), we're currently training at a school/college facility cos we don't have our own", [P6]).

c. Although peers were noted to be a cause of stress, it was interestingly an area where Heads of Welfare considered one their players needed to experience in most cases, opting for players to solve issues themselves, $(n=2)$, (e.g. "Those things just happen, its part of it, like you 'cannae get on with everyone all of the time but you have to learn to handle it", [P2]), and (e.g. "If its not affecting what we're doing then we let them sort it", [P5]. Other participants noted that having strict disciplinary procedures helps to curb certain situations was the most useful $(n=4)$, (e.g. "we had a situation last year where a lad came in with his pink boots, we told him its black boot only...they get fined for that", [P4]. One participant also acknowledged Agents as the third main barrier in terms of successfully delivering psychological support, (e.g. "You're trying to keep the lad grounded, then the agent phones him saying, oh I've got you this promotion for a film event or whatever, and they're off...so you can only do, what you can do here", [P1]).

\section{Future directions}

The results in this section identify the issues around implementing the resilience strategies, in the opinion of participants and how things may be altered to show further improvements.

a) Time was reportedly the most limiting factor in delivering psychological support to players $(n=6)$, (e.g. "It's a timing thing, coaches just want them out there (the pitch) as much as possible so anything else just gets put back whenever they can", [P3], and "Obviously we could do more, show me a club that couldn't, but, erm, our job is to produce players for the first team so that always takes first call", [P5]; and "its, erm, about developing our own players so coaching will always have the priority hands out, er... other things the coaches prioritise but it's getting out there (on the pitch)", [P4])

b) Money was reported at being the second main hindrance in terms of providing focus on psychological support, (e.g. "It's one of those things, the top clubs, have the resources, they can pay the top wages, and they can do all that, when you look at our category and we're not even training on our own pitches half the time, you just can't do it", [P6]. All clubs expressed a desire to have more psychological support for its players, (e.g. "Timing's the issues, what do you want to pay more for... recovery, coaching, physios, for us its, erm, about developing our own players so coaching will always have the priority", [P4].

c) Participants also expressed that a lack of training and/or experience of psychological processes means psychological support is not always done as efficiently as it could be. A range of reasons were given for this such as, money, time, as well as direction in terms of accessing this training, "The PFA come in and do talks with the boys twice a year, like making sure they sleep and take care of themselves", [P3]. Furthermore it appeared for one participant that this psychological support is not well- communicated on consistent across the academy, (e.g. "The Head of Education runs community workshops with them, so that involves things like motivation, health and fitness, he'll tell you later", [P5].

\section{EPPP}

Heads of Education, Welfare and Safeguarding personnel agreed the EPPP gave them a better structure for which to provide psychological support, "Aye, it's been good to get things documented, so it can follow the lad around" [P2]. However, participants' largely acknowledged that physical and technical support was still superior, "You're always going to have a physio, doctor, strength guy, but psychologists..."[P4]. Furthermore most agreed that psychological support could be improved, "Its there, they have to do it, but, the focus is still getting them out there (pitch) and playing" [P6].

\section{Discussion}

The aim of this report was to assess how well equipped Heads of Education feel about maintaining and promoting psychological welfare of players within their setting. The main stressors reported were parents, injury and peers, whilst the main barriers of implementing psychological support were time, money and education.

The use of reflexive reports and journals, to manage injury anxieties, were promoted by a number of the clubs studied. This supports Raelin ${ }^{10}$ as it allows players to apply critical thinking skills in terms of their own future directions. It was also used as a support and role-modelling activity for future year groups, supported by Hodges and Franks. ${ }^{22}$ Furthermore it encourages players to take responsibility for the learning of others as Knowles ${ }^{23}$ suggests; a process also considered by Roderick ${ }^{24}$ important in encouraging social responsibilities of young people within society. Moreover, this practice allows players to manage the day to day anxieties that adolescents encounter as suggested by Bortoli et al. ${ }^{25}$ by the cathartic process of writing down cognitions.

Most participants felt the PFA were useful in terms of taking responsibility for the psychological support of their players. Workshops were the main practical implementation of this, over the season, and some clubs had adapted these sessions for use with parents around psychological support and consistency of academy messages. However participants were less keen to promote the contributions of the FA in this process, arguing that the EPPP demands transferable skills that Head of Education, Safeguarding Officers and Psychologists do not all share commonalities with. Furthermore not all clubs felt able to subsidise support due to lack of financial expenditure. Lower category clubs in particular, highlighted facilities and coaching to be the focus of increased funding, when available, as the academies primary concern is to get players physically and technically efficient enough players to progress to their first team.

Peer influence was considered to be an important stressor if clubs encountered "problem players" or friendship anxieties caused through disagreements or the introduction of new players to the group. This may be a case for future research, in developing the disciplinary procedures for academy players. Outside influences such as agents were also a factor in one category one club, where it was felt that this authority can impact on players to too much in terms of managing their lifestyle. This contrasts to previous problems, as historically, agents were only used for overseas players, but are now a common 
feature of all players with professional contracts. Although not reported as psychological support, the demands on academy staff time was also a factor in terms of time left for delivering support. Most Heads of Education were also the club's safeguarding officer, and the paperwork associated with this role, was considered a barrier in terms of their contact time with players. It is also important to note that the EPPP demands significant amounts of paperwork to be completed annually by academy staff, therefore, if this process were to be streamlined, then academy staff may be more able to install more of their own initiatives in player support.

\section{Conclusion}

Parents, injuries and peers, remain the most common stressors experienced by academy footballers. The main ways of addressing these were found to be workshops, journals and player role-modelling. The biggest barriers to implementing successful psychological support were found to be money, time and coaching expertise. Overall Heads of Education, Welfare and Safeguarding identified the EPPP had been useful in providing better psychological support to players, but that focus was still firmly on the physical, and technical areas of development.

\section{Limitations and future direction}

Immersion into club culture remains a limitation of this study. Ideally, research would be followed up by witnessing the implementation of the resilience strategies and determining their direct effects on players. Also, players themselves could then become the subject of interview, although it is unlikely that negative features would become apparent from an outside influence posing such questions to young males wishing to succeed at their current club, despite confidentiality affirmation. On the other hand IPA analysis could then have been used to gage a reflexive itinerary of strategies in relation to club category, finances and day-to-day culture as suggested by Richards et al. ${ }^{11}$ The recommendations from this study is to run longitudinal research from within clubs, in order to gain accurate, developmental stressor effects over time in relation to the EPPP's coaching support and curriculum. This will also mean better empirical data from which to base curriculum developments and improvements over time.

\section{Acknowledgements}

The researcher would like to thank Dr Nick Davis for his contributions and support during this research.

\section{Conflict of interest}

The author declares that there is no conflict of interest.

\section{Appendix I:Written Consent Form}

Researcher's Name: Susan Jones University: Manchester Metropolitan University

Course: Post Graduate Diploma Psychology Name of Supervisor: DR Nick Davis

Title of the project: "How well is the Elite Player Performance Plan (EPPP) supporting young players with psychological welfare?

Thank you for considering being interviewed as part of this research project. Please read through the following questions and indicate your response to each of them. This is to ensure that you are fully aware of the purpose of the research and that you are willing to take part.

1. I have been informed about the purpose of the study and have had the opportunity to ask questions about it if I wished. YES/NO

2. I understand that I can withdraw from the study at any stage up to [20.04.16], without giving a reason and that my data will not be included in the research. YES/NO

In order to withdraw your data from my database which is anonymised I will need your unique, anonymous personal code. Please create an anonymous personal code now by filling in the boxes in the table below:

$\begin{array}{lll}\begin{array}{l}\text { Please insert the } \\ \text { day of the month } \\ \text { on which you } \\ \text { were born (e.g., }\end{array} & \begin{array}{l}\text { Please insert the } \\ \text { last two letters } \\ \text { of your home }\end{array} & \begin{array}{l}\text { Please insert } \\ \text { the last two } \\ \text { digits of your }\end{array} \\ \text { box below in the } & \text { AD or SU) in the } & \begin{array}{l}\text { home telephone } \\ \text { number (e.g., 02, } \\ \text { box } 98) \text { in the box } \\ \text { below }\end{array}\end{array}$

\section{Your unique,}

anonymous

personal

code is:

Table 1: Creating your unique, anonymous personal code:

3. I understand that I am free to choose not to answer a question without giving a reason why. YES/NO

4. I have been informed that the interview will be audio recorded and I give my consent for this recording to be made. YES/NO

5. I understand that extracts from the recording might be used in the research report and that this may be read by others or published later. $\mathrm{YES} / \mathrm{NO}$

6. I understand that if extracts from the recording are used any identifying information about myself and my organisation will be removed and that every attempt will be made to ensure my anonymity. YES/NO

7. I understand that the researchers have a duty to disclose the results if the results reveal current or historical harm to self or others. YES/ $\mathrm{NO}$

I give my consent to take part in the research.

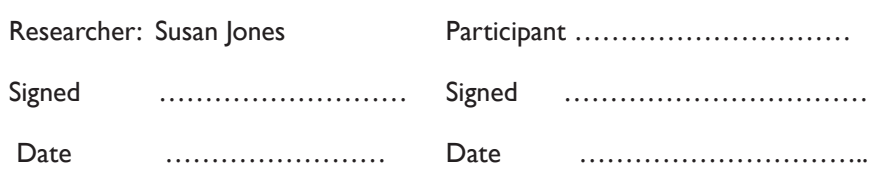

\section{Appendix 2: Participant Information Sheet}

Researcher's Name: Susan Jones University: Manchester Metropolitan University

Course: Post Graduate Diploma Psychology Name of Supervisor: DR Nick Davis

Title of the project: "How well is the Elite Players Performance Plan (EPPP) supporting young players with psychological welfare?"

You are being invited to take part in a research study. Before you 
decide, it is important for you to understand why the research is being done and what it will involve. Please take your time to read the following information carefully and discuss it with others if you wish. Ask the researcher if there is anything that is not clear or if you would like more information. Take time to decide whether or not you wish to take part.

The purpose of the research is to investigate how well the EPPP is supporting coaches and welfare officers in ensuring the mental wellbeing of their players. You have been chosen because you are within a post responsible for assisting with player mental welfare. It is up to you to decide whether or not to take part. If you do decide to take part you will be given this information sheet to keep and asked to sign a consent form.

If you agree to take part the researcher, Susan Jones will carry out a 30 minute interview, which will explore your experience of supporting psychological welfare, and will be voice recorded.

All the information that is collected from you during this research will be kept secure and any identifying material, such as names and addresses will be removed in order to ensure your anonymity. However, if during the interview any misconduct or harmThis research project forms part of my post-graduate studies and it is anticipated that the research will be written up into a report, which will be assessed. It may also be published at a later date. Your anonymity will be ensured and all the information that has been collected about you will be kept secure. The researcher will destroy all copies of the data on completion of their degree. However, if the anonymised data is to be used in further publications, it will be passed to my research supervisor for safekeeping.

If you decide to take part you are still free to withdraw your data from the study after participation. Please note that you can do this until 01.05.16 after which the researcher will have already conducted the analysis of the data. If you wish to withdraw from the study please contact the researcher13164908@stu.mmu.ac.uk

If you require any further information about the research please contact the researcher, 13164908@stu.mmu.ac.uk or the research supervisor Dr Nick Davis: n.davis@mmu.ac.uk

Thank you for reading this information sheet and considering participation in my research.

\section{Appendix 3: Interview Schedule}

1. Could you elaborate a little about your role please?

2. What are your experiences about how well that role integrates into the academy structure/philosophies? (examples?)

3. How have your experiences as Head of Welfare changed since the EPPP introduction? (Examples)

4. How well do you think the EPPP defines the expectations on your role in supporting players' mental health?

5. In your experience what are the main barriers to securing good mental health of players? (examples?)

6. What have you found useful at combatting these effects? (examples?)

7. In your experience what are the main issues in terms of providing these supporting practices for players? (examples?)

8. Do you perceive these changing over time? (Why/How)?

9. Anything else about implementing the EPPP you wish to comment on in terms of its support of players psychological wellbeing?

Thank them, give debrief sheet.

\section{Appendix 4: De-brief Sheet}

Name of Researcher: Susan Jones University: Manchester Metropolitan University

Course: Post Graduate Diploma Psychology Name of Supervisor: DR Nick Davis

Project Title: "How well is the Elite Players Performance Plan (EPPP) supporting young players with psychological welfare?"

Thank-you for taking part in my research. The data you contributed will help me to complete my empirical project which is focussed on wellbeing in youth football and aimed to represent how well the EPPP is working in practice.

If you have any questions about my study please feel free to ask them now. If you would like to request a summary of my research findings you can do from 01.05 .2016 to 31.08 .2016 by emailing me 13164908@stu.mmu.ac.uk

Your data will be kept securely and anonymised. At the end of my degree I will destroy any copies I have of the data. However, if it is to be considered for use in publications, it will be passed to my Research Supervisor for safekeeping. If you wish to withdraw your data you can do so at any point up to 20.04.16 after which I will have commenced my data analysis

In order to withdraw your data from my data base which is anonymised I will need your unique, anonymous personal code. Please create an anonymous personal code now by filling in the boxes in the table below:

Table 1 Creating your unique, anonymous personal code:

\begin{tabular}{|c|c|c|c|}
\hline & $\begin{array}{l}\text { Please insert the } \\
\text { day of the month } \\
\text { on which you were } \\
\text { born } \\
\text { (e.g., } 04 \text { or } 12 \text { ) } \\
\text { in the } \\
\text { box below }\end{array}$ & $\begin{array}{l}\text { Please insert } \\
\text { the last two } \\
\text { letters of } \\
\text { your home } \\
\text { postcode (e.g. } \\
\text { AD or SU) in } \\
\text { the box below }\end{array}$ & $\begin{array}{l}\text { Please insert } \\
\text { the last two } \\
\text { digits of your } \\
\text { home telephone } \\
\text { number (e.g., } \\
02 \text {, or } 98 \text { ) in the } \\
\text { box below }\end{array}$ \\
\hline $\begin{array}{l}\text { Your unique, } \\
\text { anonymous } \\
\text { personal } \\
\text { code is: }\end{array}$ & & & \\
\hline
\end{tabular}

\section{Appendix 5: Sample of Annotated Interview Transcript (P3)}

SJ: Can I just confirm for the tape please that you have signed a consent form and have been given an information sheet?

Yes

SJ: Thank you. Now you are the Head of Welfare here at "Academy Name", could you tell me a little bit about what that involves day to day? 
Yeah well as Head of Welfare I am responsible for the lads needs when theyre in and around the academy, so visas, health and safety, DBS stuff like that...(sigh) then I look at they're issues like if they've had a bad day, school or whatever, make sure they're coping, like give them a nudge or whatever and try and sort out anything where we can.

SJ: Can you give any examples of those issues at all or anything?

Yeah yeah so um like if you've got a kid not doing well in exams we might say, let's get him in with the Education department and give him some one-to-one like...so its um monitored and we're seen to be... on top of that kid

SJ: Yeah, yeah, so you try and integrate everything into the academy for them?

Yeah where we can, we want to know what they're doing so they're happy here and want to continue with us...you know its not just about making sure that particular lads ok its about the bigger, picture, are they gonna be here next year?...You know for the Club... that's everything really, we need to bring lads into the first team to um support that infrastructure, if were not then were gonna loose boys here and there and that's not to look good on us and what we're doing?

SJ: So is it about demonstrating that then, maybe, as much as anything else, to the players?

Not so much for the players cos they know were here to help them, but for us like then yeah cos you know we need to be seen to be doing our job for the club not just the lads and that

SJ: So do you find the club's philosophies match that then in terms of what you're doing here to what they need you to be doing?

Um you mean like in terms of club philosophy or our philosophy as officers?

\section{SJ: Both really, is it different?}

Well it can be...like the club wants good first team players, now our job is to get them to that stage so we want them to be good first team players but we get all the other stuff like the day to day stuff that the first team don't see, so... whilst... perhaps were working on a lot of the social and developmental stuff, which is important the first team don't really "need" us to see that that when they go there.

SJ: Right I see so as long as they can be first team ready, the other stuff is...not so...detailed maybe that the first team see?

Yeah yeah absolutely, and that's fine cos you know theyre at the top end getting results and that that's their job and we need to do ours right so that's right

SJ: Yeah ok...thank you. So...what kind of things do you have to see daily then in terms of the stress that your young players come under while they're here with you?

Parents. Keeping them happy cos you want them to keep their lads here so you have to do a lot of work with them to get them on board.

SJ: Is that something you do a lot then here with the parents, how you work and get them involved?

Yeah yeah absolutely, so well invite them in once or twice a year and tell them what's been happening, what we've done, etc, what they can be doing with them at home to help that etc, you don't want parents to be... too involved like but if they know what we're doing its easier...like theyre more into it and happier that theyre part of it... cos...you know they do invest a lot...you know in terms of money and time...preparing them... getting them to games and stuff so its important theyre involved throughout that and we can get them to see that were doing things right and then it helps that

SJ: Right, so do you run those workshops or do you get other people involved?

It depends...like progressive ones they have with the manager are done with us but if its like an FA thing like smoking or something then they come in and do that, or PFA, sometimes charities...depends

\section{SJ: OK, do you find the lads react differently to those then?}

They can do yeah so you have to make it interesting for them and so they know its good for them so we might like let's say make a competition out of it or get them into... like teams for some of them and that's always good cos they're more willing to get involved then

\section{SJ: Yeah yeah}

Also you might like get them to design things for each other so if its lifestyle stuff we might get them to design a leaflet for each other or something, cos that's something they are happier to do then whereas if we get them to just write stuff down then you might not get as much back

SJ: Yeah, so do you use that for other stressful situations then or is it...like directed

Yeah injuries they'll do leaflets on and stuff, we might get "name omitted" the physio down to do some stuff with them cos he knows them and does all that so again its about keeping them involved. And with injuries we get the lads to write about the time injured cos then we can use it, for others, its great cos they feel like they're helping us but they're also helpin themselves.

\begin{tabular}{lll}
\hline Job Profile & Stressor & Support Staff \\
Resilience Strategy & Barriers & Club Culture \\
EPPP negatives & EPPP Positives &
\end{tabular}

\section{References}

1. Wylleman P, Lavallee D. A developmental perspective on transitions faced by athletes. In: Weiss M, editor, Developmental sport psychology'. Morgan town, WV: Fitness Information Technology; 2004:503-524.

2. Brown G, Potrac P. 'You've not made the grade son: deselection and identity disruption in elite level youth football'. Soccer and Society. 2009; 10(2):143-149.

3. American Psychiatric Association. Diagnostic and Statistical Manual of Mental Disorders. $5^{\text {th }}$ edn, Arlington: VA; 2013.

4. Alfermann D. Causes and Consequences of Sport Career Termination. In: Lavallee D, Wylleman, editors. Morgantown, Career Transitions in Sport: International Perspectives. WV: Fitness Information Technology; 2000:49-58

5. Finn J, McKenna J. Coping with Academy-First team transitions in Elite Male Team Sports: The coaches' perspective. International Journal of Sports Science \& Coaching. 2010;5(2):257-279.

6. Drahota JAT, Eitzen DS. The role of exit of professional atheltes'. Sociology of Sport Journal. 1998;15(3):263-278. 
7. PFA. Life as a Professional Footballer and How to Handle it'. The Professional Football Association: Organisation Press; 2013.

8. Holt NL, Dunn JGH. Toward a grounded theory of the psychosocial competencies and environmental conditions associated with football success. Journal of Applied Sport Psychology. 2014;16(3):199-219.

9. Sagar SS, Busch BK, Jowett S. Success and Failure, Fear of Failure and coping responses of Adolescent Academy Football Players'. Journal of Applied Sport Psychology. 2009;22(2):213-230.

10. Raelin J. I don't have time to think! versus the art of reflective practice'. Reflections. 2002;4(2):65-79.

11. Richards $\mathrm{P}$, Mascarenhas DRD, Collins D. Implementing reflective practice approaches with elite team athletes: Parameters of success'. Reflective Practice. International and Multidisciplinary Perspectives. 2009;10(1):353-363.

12. Folkman S, Moskowitz JT. Coping: Pitfalls and Promise. Annual Review of Psychology. 2003;55(1):745-774.

13. Brannen $\mathrm{C}$, Petite $\mathrm{K}$. An alternative framework for understanding women's caregiving stress-A qualitative application of the ways of coping model. Journal of Health Psychology. 2008;13(3):355-365.

14. The Premier League. The Elite Player Performance Plan. 2011.

15. Dale GA, Wristberg CA. The use of a performance profiling technique in a team setting: Getting the athlete and coach on the "same page". Sport Psychologist. 1996;10(3):261-277.

16. Levitt C. Addressing a Crisis. Canadian Family Physician. 1999;45:553555.
17. Cote J, Salmelaj J, Trudelp. The Coaching Model- A Grounded Assessment of Expert Gymantic Coaches Knowledge'. Journal of Sport \& Exercise Physiology. 1995;17(1):1-17.

18. Kvale S. The Qualitative Research Interview- A Phenomenological and a Hermenteutical Mode of Understanding. Journal of phenomenological psychology. 1983;14(2):171-196.

19. Smith JA. Semi-structured interviewing and qualitative analysis. In: Smith JA, Hare R, Van Langenhove L, editors, Rethinking methods in psychology. London: Sage; 1995.

20. Biddle SJH, Markland D, Gilbourne D, et al. Research methods in sport and exercise psychology: Quantitative and qualitative issues'. Journal of Sports Sciences. 2001;19(10):777-809.

21. Patton MQ. Qualitative research \& evaluation methods. $3^{\text {rd }}$ edn, Thousand Islands, CA: Sage;2002.

22. Hodges NJ, Franks IM. Modelling coaching practice: the role of instruction and demonstration'. Journal of sports sciences. 2002;20(10):793-811.

23. Knowles M. The adult learner. $6^{\text {th }}$ edn. Burlington, MA: Elsevier. 2005

24. Roderick M. A very precarious profession: Uncertainty in the working lives of professional footballers'. Work Employment \& Society. 2006;20(2):245-265.

25. Bortoli L, Messina G, Zorba M. Contextual and individual influences on antisocial behaviour and psychobiological states of youth soccer players'. Psychology of Sport and Exercise. 2012;13(4):397-406. 